
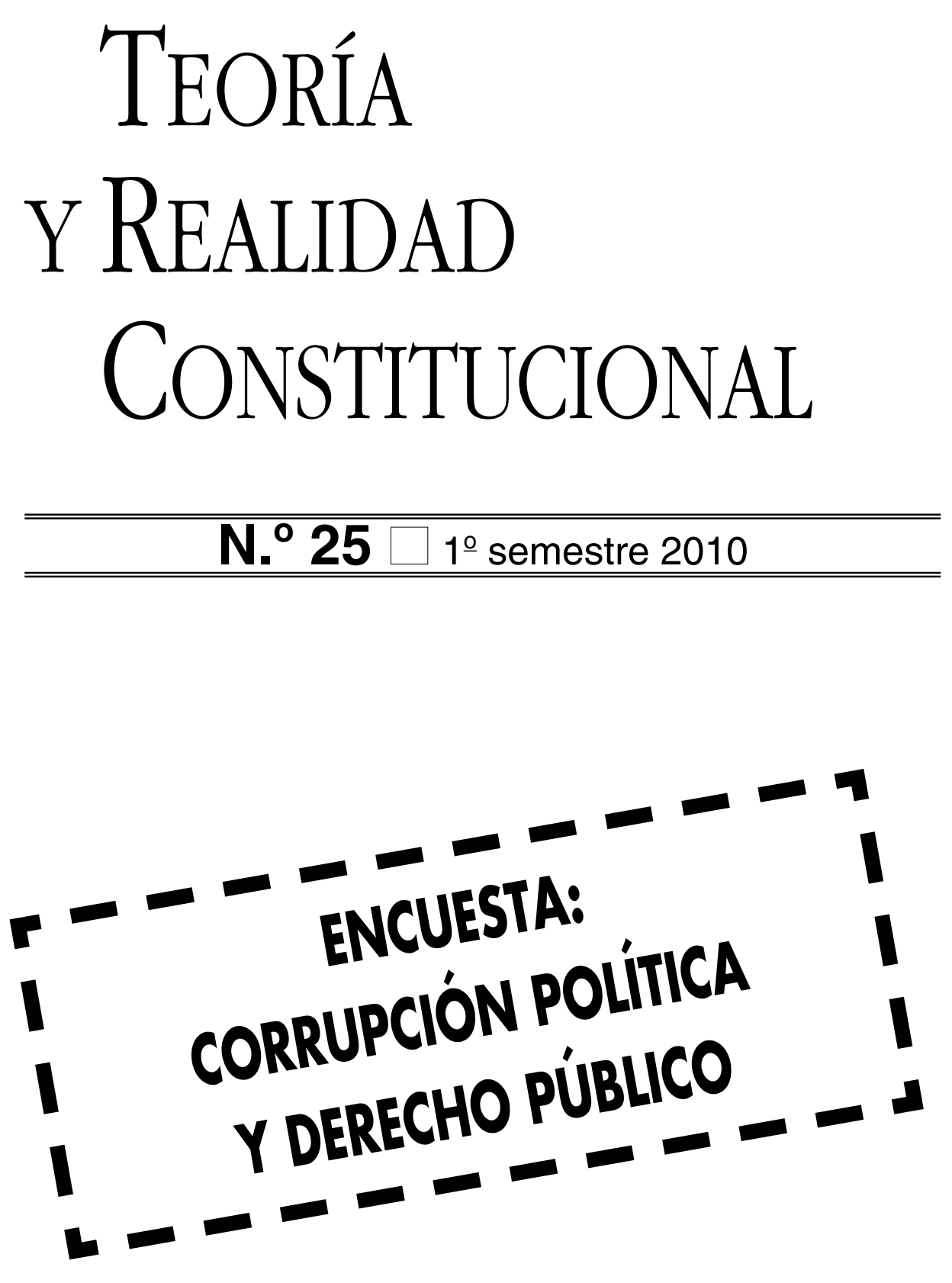


\title{
LA TRAYECTORIA INTELECTUAL Y POLÍTICA DE ADOLFO POSADA
}

\author{
JOAQUÍN VARELA SUANZES-CARPEGNA \\ Catedrático de Derecho Constitucional
}

\author{
SUMARIO \\ I. Los años de formación. \\ II. Catedrático en Oviedo. \\ III. En el Instituto de Reformas Sociales y \\ en la Universidad madrileña. \\ IV. La jubilación, el exilio, la muerte.
}

\section{LOS AÑOS DE FORMACIÓN}

Adolfo González Posada nació en Oviedo el 18 de septiembre de 1860, en el seno de una familia dedicada al comercio. Estudió el bachillerato en el Instituto de su ciudad natal y se graduó en 1874. En ese mismo año ingresó en la Facultad de Derecho de la capital asturiana, en la que se licenció en 1878. Su primer contacto con el Derecho Político no fue muy edificante: "más que en clase", lo aprendió en "los libros de Colmeiro", sobre todo en el llamado "Colmeiro el pequeño", que era, en palabras de Posada, "una especie de remediavagos muy en uso en nuestras Universidades ${ }^{1}$. No obstante, en el segundo año de Derecho Político las cosas cambiaron debido a la llegada de un sugestivo aunque fugaz profesor — tan fugaz que no logra recordar su nombre- y sobre todo a las clases que sobre este particular se vio obligado a impartir Rafael de Ureña, en quien "parecía germinar alguna semilla del krausismo recogida en Ahrens y en Giner, planta, por lo demás, para mí des-

1 Fragmentos de mis Memorias, Prólogo de E. ALARCOS, Servicio de Publicaciones de la Universidad de Oviedo, Oviedo, 1983, págs. 68 y 75. Se refiere POSADA a los Elementos de Derecho Politico y Administrativo de España, cuya primera edición es de 1858. Me ocupo del lugar de COLMEIRO en el Derecho Político español en ¿Qué ocurrió con la ciencia del Derecho Constitucional en la España del siglo XIX?, que recojo en mi reciente libro Política y Constitución en España, 1808-1978, Centro de Estudios Políticos y Constitucionales, Madrid, 2007, prólogo de F. RUBIO LLORENTE. 
conocida ${ }^{2}$. Este desconocimiento no duraría mucho, sin embargo, pues por aquellos años Posada se topa con un ejemplar del Ideal de la Humanidad para la vida, de Krause, cuyo "sabor místico" le atrajo de manera muy espe$\mathrm{cial}^{3}$. El krausismo, de tanto influjo en la intelectualidad española de la segunda mitad del siglo XIX ${ }^{4}$, sería la filosofía que más impacto tendría en su obra e incluso en su vida.

Tras terminar sus estudios de Derecho, Posada se trasladó a Madrid a cursar Filosofía y Letras, pero pronto abandonó esa carrera y la capital de España al comprobar que muchos de los mejores profesores habían sido apartados de sus cátedras por Orovio, Ministro de Fomento en el Gobierno de Cánovas del Castillo, el artífice de la Restauración. Un régimen político con el que el profesor asturiano se mostraría siempre muy crítico.

Posada regresó a Madrid en 1879 y en diciembre del año siguiente obtuvo el título de Doctor en Derecho por la Universidad Central con una Tesis sobre las Relaciones entre el Derecho Natural y el Derecho Positivo. Este título hoy nos asombra por su amplitud, pero es preciso temer en cuenta que entonces se escogía entre un cuestionario impuesto por la propia Universidad Central, que era la única con capacidad para expedir el grado de Doctor. Con este sistema, que Posada no deja de criticar, la Tesis "se convertía en un trámite académico consistente en la respuesta escrita a una pregunta o cuestión de un programa dado" ${ }^{5}$. En su Tesis se percibía la impronta del krausismo y de Ihering, de quien tradujo, en 1881, La Lucha por el Derecho, con un Prólogo de Leopoldo Alas, "Clarín". De acuerdo con estas influencias, Posada "procuraba distinguir, no separar, y menos oponer, el Derecho Natural y el Positivo... comprendidos ambos en la unidad inagotable del Derecho en la vida..." ${ }^{6}$.

De las observaciones que le hicieron los miembros del Tribunal Posada sólo recuerda una, la de su Presidente, José Moreno Nieto, "gran apóstol del espiritualismo", que merece la pena, y mucho, reproducir aquí, pues resulta muy ilustrativa del ambiente antipositivista que se respiraba en la Universidad española:

“... después de aplaudir la tendencia general de la Tesis (escribe Posada refiriéndose al bueno de Don José), aprovechó una de mis intervenciones para arremeter contra los positivistas:

2 Fragmentos de mis Memorias, op. cit, págs. 76-77.

3 Cfr. ibidem, pág. 79

4 Me extiendo sobre este influjo, muy en particular en lo que atañe al Derecho Político, en $E l$ Derecho Político en Adolfo Posada, que incluí en mi libro Asturianos en la política española. Pensamiento y Acción, KRK ediciones, Oviedo, 2006. Para ello tengo muy en cuenta, aparte de las propias fuentes originarias, los estudios del propio Posada, así como los de J.J. GIL CREMADES, E. DÍAZ y J.A. PORTERO MOLINA.

5 Fragmentos de mis Memorias, op. cit, pág. 131

6 Ibidem, pág. 139. Esta tesis se publicó en 1881 en la "Revista de Legislación", de la editorial Reus. 
—No niego — decía don José- que los hay que saben hacer pucheros y son excelentes "pucherólogos". Pero, ¿para qué sirven los pucheros vacíos? Lo que importa es saber y tener con qué llenarlos".

- Con el ideal, ¿verdad?, me atreví a decir.

-Claro, hombre, claro" ${ }^{7}$.

En la capital del España, en la que permaneció cuatro años, Posada asistió también a los Cursos que impartía la Institución Libre de Enseñanza, con cuyos creadores, Francisco Giner de los Ríos y Gumersindo de Azcárate, dos de los Catedráticos expulsados por Orovio, Posada comenzó a trabar una decisiva y duradera amistad ${ }^{8}$. En realidad, tanto la vida como la obra del profesor asturiano iban a estar estrechamente ligadas a estos dos grandes liberales. En lo que concierne a Giner, Posada reconoce en sus Memorias el ascendente que en toda su obra ejerció el Curso que, con el título de Principios de Derecho Político, el profesor malagueño impartió en la madrileña sede de la Institución Libre de Enseñanza a lo largo de 1880 o 1881 (la fecha exacta no la recuerda) y que nunca llegaría a publicarse. "Para mí fue una verdadera revelación", dirá Posada9, quien añade que el Curso de Giner "centró o, mejor, dio cierta cohesión — ique buena falta le hacía! — a mi formación, dispersa, fragmentaria, en lo referente a la Filosofía del Estado...."10.

En su Breve historia del krausismo español, Posada, tras reconocer de nuevo el impacto de este Curso, recuerda que en él Giner apostaba por un

"derecho político de abolengo krausista, sin duda, por su base ética, sus supuestos metafísicos y su sentido esencialmente orgánico, pero de una profunda originalidad frente a las tendencias entonces invasoras del organicismo sociológico... Giner —concluía Posada - contribuyó como nadie, quizá, a afirmar la sustantividad del Derecho Político, disciplina distinta de la Política y del Derecho Constitucional y del llamado Derecho Público, y contribuyó también a la rectificación de la clásica división del Derecho —en público y privado-, tan característica de lo que algunos, no sé si con precipitación o exageración, llaman escuela jurídica española: jurídica y política, diría yo" ${ }^{11}$.

Este Curso, junto a los Principios de Derecho Natural (1871), del mismo autor, fueron, revela Posada,

7 Ibidem, pág. 139.

8 Sobre la Institución Libre de Enseñanza durante estos años, vid. el clásico estudio de V. CACHO VIU, La Institución Libre de Enseñanza. Orígenes y etapa universitaria (1860-1881), Rialp, Madrid, 1962.

9 Fragmentos de mis Memorias, op. cit. pág. 147.

10 Ibidem, pág. 147.

11 Breve historia del krausismo español, Servicio de Publicaciones de la Universidad de Oviedo, 1981, págs. 85-86. Al influjo de este Curso volverá a aludir POSADA en El Derecho político como espectáculo. Cincuenta años de Cátedra, Tipografía de Archivos, Madrid, 1933, pág. 9. 
"mis "andadores" en la elaboración de la Teoría del Estado que había de constituir la preocupación central de mi espíritu en los cincuenta años de cátedra en Oviedo, en Madrid y en alguna cátedra hispano-americana, especialmente en las Universidades de La Plata y de Buenos Aires en la República Argentina " ${ }^{12}$.

En lo que atañe a Gumersindo de Azcárate, Posada lo califica en sus Memorias de "consejero y guía". "Lo que yo le debo a Azcárate — añade— no sabría decirlo y menos explicarlo, ¿para qué? Le debo en buena parte la formación de mi íntimo ser moral" ${ }^{13}$. A su juicio, el intelectual leonés fue "el más honesto, desinteresado, competente, respetable y respetado de los hombres públicos españoles " ${ }^{14}$.

Pero aparte de sus estudios de doctorado y de sus cursos en las Institución Libre de Enseñanza, Posada frecuentó en Madrid la "rica biblioteca" del Ateneo, en la que preparó sus oposiciones a Cátedra, y sus a veces animados debates, además de participar en diversas tertulias, como la del "Fornos" y luego la de "La Cervecería Inglesa" —llamada por Ortega Munilla el "Bilis Club", injustamente, según Posada. A esas tertulias asistían, entre otros muchos, sus paisanos Armando Palacio Valdés y Leopoldo Alas. Con este último mantuvo una gran amistad, primero en Madrid y luego en Oviedo, conversando sobre las más diversas cuestiones y leyendo juntos a los novelistas franceses y rusos así como a los poetas alemanes.

\section{CATEDRÁTICO EN OVIEDO}

En 1883 — cuando sólo contaba 23 años, que así de rápido se hacían entonces estas cosas - Posada obtuvo por unanimidad la Cátedra de "Elementos de Derecho Político y Administrativo" de la Universidad de Oviedo. El Tribunal que se la otorgó estaba compuesto por Juan Uña, Consejero de Instrucción Pública, el ex Ministro de Hacienda Laureano Figuerola, Gumersindo de Azcárate, reintegrado a su Cátedra por el Gobierno Sagasta, Juan Hinojosa, hermano del ilustre historiador del Derecho, Concha Alcalde, Registrador de Salamanca, y dos asturianos muy amigos suyos: Adolfo Alvarez Buylla y Leopoldo Alas ${ }^{15}$.

Ese mismo año de 1883 se incorporó a la Facultad de Derecho de Oviedo, de la que formaban parte, entre otros, los mencionados Adolfo Alvarez Buylla y Leopoldo Alas, así como Fermín Canella. Destacados miembros todos ellos, como el propio Posada, de lo que Joaquín Costa llamó «movimiento de Oviedo" ${ }^{16}$, al que se sumaron más tarde Aniceto Sela, Rafael Altamira y el gran tribuno republicano Melquíades Álvarez. A ese "movimiento" o "grupo" perte-

12 Fragmentos de mis Memorias, op. cit. pág. 148.

13 Ibidem, pág. 321.

14 Ibidem, pág. 312.

15 Cfr. ibidem, pág. 166.

16 POSADA recuerda la denominación de COSTA en sus Memorias, op. cit. pág. 178. 
necían algunos profesores de ideología conservadora, como Guillermo Estrada y Matías Barrio y Mier, pero animados también de una ejemplar entrega a las tareas universitarias.

En 1884 Posada da a la imprenta un libro titulado Principios de Derecho Político, que, como él mismo confiesa, se inspiraba en el antes comentado Curso que Giner había expuesto sobre esta materia en la Institución Libre de Enseñanza y que le sirvió también para preparar sus oposiciones a Cátedra ${ }^{17}$.

En este libro juvenil y un tanto precipitado, como reconocería su autor ${ }^{18}$, Posada, recordando lo dicho por Ahrens en la Enciclopedia Jurídica o Exposición orgánica de la Ciencia del Derecho y del Estado (escrita en alemán en 1855 y vertida al español en 1878), señalaba que "el cuadro de las Ciencias particulares que comprende la Enciclopedia del Derecho Político" abarcaba la "Filosofía del Derecho Político", la "Historia del Derecho Político" y la "Filosofía de la Historia del Derecho Político" ${ }^{19}$. Ahora bien, en los Principios Posada añadía por su cuenta consideraciones propias de otras ciencias, fundamentalmente la Sociología, pero también la Biología y la Psicología.

Durante estos primeros años como catedrático, merece la pena destacar también el libro que publicó en 1891 con el título Estudios sobre el Régimen Parlamentario en España $(1891)^{20}$, en el que ponía al descubierto los aspectos menos edificantes del sistema canovista. Algo que ya había hecho Gumersindo de Azcárate en El régimen Parlamentario en la práctica (1885).

Un par de años después, retomando lo que había esbozado en sus Principios de Derecho Político, Posada dio a la imprenta el Tratado de Derecho Político, que constaba de tres tomos. El primero se dedicaba a la "Teoría del Estado" y el segundo al "Derecho Constitucional Comparado de los principales Estados de Europa y América", mientras que el tercero se titulaba "Guía para el estudio y aplicación del Derecho Constitucional de Europa y América (cuestionarios, textos y bibliografía) ${ }^{21}$.

Al distinguir entre "Teoría del Estado" y "Derecho Constitucional Comparado", la división tripartita del Derecho Político sustentada por Ahrens -que Santamaría de Paredes ya había acogido $^{22}$ — da paso, pues, a otra bipartita, to-

17 Cfr. Fragmentos de mis Memorias, op. cit, págs. 148-9 y 227. Sin embargo, en el Prólogo de este libro Posada no menciona a GINER y sí, en cambio, a MACAULAY y a TAINE, a quienes se lo dedica. Cfr. Prólogo a Principios de Derecho Político. Introducción, Imprenta de la Revista de Legislación, Madrid, 1884.

18 Cfr. Fragmentos de mis Memorias, op. cit. pág. 227.

19 Principios... op. cit. pág. 184.

20 Este libro lo reeditó la Junta General del Principado de Asturias en 1996, dentro de su colección "Clásicos Asturianos del Pensamiento Político", con un interesante y extenso Estudio Preliminar de F. RUBIO LLORENTE.

21 A. POSADA, Tratado de Derecho Político, Librería de Victoriano Suárez, Madrid, 1893-1894. La "Guía" se agotó rápidamente, pero no volvió a imprimirse, al quedar insatisfecho su autor, $c f r$. Fragmentos de mis Memorias, op. cit. pág. 277.

22 Cfr. V. SANTAMARÍA DE PAREDES, Curso de Derecho Político, $1^{a}$ edición, Valencia, 1880 1881. Sobre este Curso me extiendo en mi citado trabajo ¿Qué ocurrió con la ciencia del Derecho Constitucional...? 
mada de Bluntschli. Una división que mantuvo en las sucesivas ediciones del Tratado, que se publicaron ya en el siglo XX, con gran fortuna, sobre todo la quinta y última, la más completa de todas, que vio la luz en 1935, y en donde se define al Derecho Político como el "Derecho del Estado" 23.

Ahora bien, la distinción entre "Teoría del Estado" y "Derecho Constitucional Comparado" encubría en realidad una idea enciclopédica del Derecho Político, que se había puesto de relieve diez años antes en los Principios, según se ha visto. Una idea que el propio Posada reconocía abiertamente al señalar que su Tratado abarcaba "aquellas materias que son sin duda las más importantes en la actualidad dentro de la Enciclopedia del Derecho Politico ${ }^{24}$.

Como he mostrado en otro lugar ${ }^{25}$, a partir de este concepto de Derecho Político, muy próximo al de la Ciencia Política, el maestro asturiano, lejos de vertebrar en España una ciencia del Derecho Constitucional, centrada en el estudio de la Constitución vigente (una ciencia que por aquel entonces auspiciaban Laband y Jellinek en Alemania, Orlando en Italia, Dicey en la Gran Bretaña, y Esmein y Carré de Malberg en Francia), consolidó una asignatura enciclopédica, en la que los aspectos jurídicos ocupaban un lugar muy secundario. Cierto que la vigente Constitución de 1876, cuyo valor normativo fue muy escaso, cuando no nulo, sin que sirviese tampoco para ordenar el proceso político ${ }^{26}$, no ayudaba a articular una ciencia del Derecho Constitucional. Pero, como también he puesto de relieve en otra ocasión ${ }^{27}$, las causas del alejamiento de Posada de esta ciencia y su inclinación por la Ciencia Política, se debían a su rechazo del positivismo jurídico y al peso de un concepto material de Constitución, hegemónico a lo largo de nuestro siglo XIX, ya fuese histórico (como el que formularon Jovellanos y Cánovas) o sociológico (por el que se decantó Posada) o ambas cosa a la vez. Buena prueba de lo que aquí se sostiene es que bajo la vigencia de la Constitución de 1931, concebida como norma jurídica suprema y que coherentemente puso en planta un Tribunal de Garantías Constitucionales, Posada siguió dedicando en la quinta y última edición de su Tratado tan pocas páginas como las que le

23 Tratado de Derecho Político, t. 1, Madrid, 1935, pág. 54.

24 Tratado, t. I, Madrid, 1893, pág. 7.

25 El Derecho Politico en Adolfo Posada, op. cit. A la hora de delimitar los conceptos de Derecho Político, Derecho, sociedad, Estado y Constitución sustentados por Posada, tengo muy en cuenta, además de lo dicho por RUBIO LLORENTE en su ya citado Estudio preliminar, la monografía de F. J. LAPORTA, Adolfo Posada: política y sociología en la crisis del liberalismo español, Editorial Cuadernos para el Diálogo, Madrid, 1974, pág. 88. Junto a una biografía de POSADA y a un repertorio de sus muchas obras (págs. 13-85 y 344-352, respectivamente), este libro sigue conteniendo todavía hoy la más completa exposición del pensamiento político y social del Catedrático asturiano, al que LAPORTA califica como "el teórico krausista del Estado por excelencia", pág. 88.

26 Me ocupo de ello en mi reciente monografía La Constitución de 1876, Iustel, 2009, volumen VII de la colección "Las Constituciones Españolas", dirigida por M. ARTOLA.

27 ¿Qué ocurrió con la ciencia del Derecho Constitucional en la España del siglo XIX?, op. cit. Vuelvo sobre ello en Constitución, Estado y derechos fundamentales en España desde la Restauración canovista hasta la actualidad, que se encuentra recogido también en mi citado libro Política y Constitución en España. 
había dedicado antes en este libro a la Constitución de 1876, de naturaleza no muy distinta, por otra parte, a las vigentes en la Europa del último tercio del siglo XIX y comienzos del XX. En cambio, en el segundo volumen del Tratado Posada expone de manera pormenorizada, aunque es verdad que casi siempre meramente descriptiva, el derecho público de la Gran Bretaña, de los Estados Unidos, de Francia y de Alemania.

La escasa importancia que el ordenamiento y la doctrina españolas tienen en la obra de Posada, frente a las constantes referencias a los ordenamientos y doctrinas extranjeros, ha llevado incluso a algún autor a hablar de una "desnacionalización" del Derecho Político por parte del publicista asturiano ${ }^{28}$.

El Tratado, aparte de su enorme influencia en el Derecho Político español y de convertirse en libro de texto en alguna Universidad hispano-americana, se tradujo al italiano en 1902 y un extracto al alemán en 1913. Sobre la relevancia del Tratado, sin suda su obra cumbre, se pronunciaría el propio Posada en sus Memorias al hacer el balance de su dilatada producción científica:

"Todo cuanto he trabajado en ciencia política - filosófica y positiva- lo he trabajado en y para este "Tratado", que estimo la obra capital de mi larga vida de profesor, de investigador y de publicista.... ${ }^{29}$.

Pero en la capital asturiana la labor de Posada no se limitó a escribir obras académicas. Con Buylla, Canella, Alas y Sela, Posada fundó en 1895 la "Escuela de Estudios Jurídicos y Sociales" y tres años más tarde la "Extensión Universitaria", dependientes ambas de la Universidad de Oviedo, entonces la más pequeña de España, pero que llegó a alcanzar por esos años un gran prestigio. Con la "Escuela" se intentaba sustituir la clásica lección magistral por el debate de un tema monográfico expuesto ante un reducido grupo de alumnos voluntarios, siguiendo el ejemplo alemán del seminario. Con la "Extensión Universitaria" se pretendía difundir la cultura entre la clase obrera. Eso sí, sin degradarla, pues si Adolfo Posada, de acuerdo con la mejor tradición liberal española (la más sólida base de regeneración nacional desde la Ilustración), detestaba el clasismo, que impedía el acceso a la Universidad a muchas personas valiosas por razones puramente económicas, con igual fuerza mantenía una imprescindible actitud elitista hacia la Universidad, cimentada en la

28 Cfr. A. GALlEGO ANABITARTE, Las asignaturas de Derecho Político y Administrativo: el destino del Derecho Público español,, "Revista de Administración Pública", n ${ }^{\circ}$ 100-102, vol. I, enero-diciembre, 1983, pág. 781. Esta "desnacionalización” trataría de justificarla, en 1932, N. PÉREZ SERRANO, el más importante discípulo de Posada y su sucesor en su Cátedra madrileña, por haber vivido España hasta entonces "en un período de asimilación de instituciones extranjeras, de examen de otras técnicas, de copia incluso de investigadores que se nos adelantaban en otros países. A ello contribuía nuestro doloroso retraso con respecto a las corrientes científicas del mundo...", Estudio acerca del concepto, método, fuentes y programas del Derecho Político Español comparado con el extranjero, en Escritos de Derecho Político, Instituto de Estudios de Administración Local, Madrid, 1984, Vol. I, págs. 33-4.

29 A. POSADA, Fragmentos de mis Memorias, op. cit, pág. 277. 
aristocracia del talento y del trabajo, sin la cual no hay Universidad digna de ese nombre. En el mismo año de 1898 Posada fundó también, en unión de Rogelio Jove y Félix de Aramburu, otros destacados miembros del "grupo de Oviedo", las Colonias Escolares de Salinas ${ }^{30}$.

En la Universidad ovetense permaneció Posada veinte años. Durante ellos continuó estudiando a fondo todos los problemas fundamentales del derecho, del Estado y, por supuesto, de la sociedad. Es muy significativo que cuando Posada rememora, con nostalgia y cariño, sus años de Catedrático en la capital asturiana, recuerde el goce intelectual que le producían sus reflexiones sociológicas:

"... lo que me he divertido cavilando sobre si la sociedad es un "organismo" con sus células y sus tejidos... y sobre si el objeto de la Sociología es el "ser social" o el "hecho social", o "lo social" sencillamente... y conversando, por correspondencia, con mis buenos amigos Gabriel Tarde, René Worms, Gaston Richard, Francesco Nitti, F. H. Giddins, Novicow, etc, etc...”31.

Porque, en efecto, aparte del decisivo ascendente de la filosofía krausista, en Posada resultó muy poderosa la influencia del positivismo sociológico, base científica de la naciente Sociología, de la cual fue Posada uno de los primeros cultivadores en España. El impacto de la Sociología se detecta ya en sus ya comentados Principios de Derecho Político (1884), para manifestarse de forma más explícita y madura en su estudio Teorias modernas acerca del origen de la familia, de la propiedad y del Estado, que se publicó en 1892 y se tradujo luego al francés. Pero en Posada se percibe también la huella del positivismo biológico, psicológico e histórico. De este manera, autores como Spencer, Wundt, Tarde, Taine y Savigny están presentes ya en sus primeras obras, particularmente en el Tratado. En cambio, Posada, como los demás krausistas, se sintió muy distante, como queda dicho, del positivismo jurídico, sobre todo del alemán, que serviría de cimiento a la articulación del Derecho Constitucional en Europa.

A lo largo de estas dos décadas ovetenses Posada se vio obligado a completar su magro sueldo de Catedrático —que en su primer año no pasaba de 3.500 pesetas anuales - con una asidua colaboración en la prensa regional y madrileña, así como con diversas traducciones del francés, del alemán y del inglés, idiomas que, junto al italiano y al portugués, leía sin dificultad ${ }^{32}$. Po-

30 Sobre la Universidad de Oviedo durante la época en que Posada fue catedrático, vid. tres trabajos de S. MELÓN FERNÁNDEZ, Un capítulo en la historia de la Universidad de Oviedo, La Extensión Universitaria: antecedentes y características y El conflicto universitario de 1884 en la Universidad de Oviedo, recogidos en Estudios sobre la Universidad de Oviedo, Oviedo, 1998, págs. 1785, 86-114 y 175-204, respectivamente. Vid. asimismo, el más reciente trabajo de G. CAPELLÁN DE MIGUEL, Intelectuales, Universidad y Opinión Pública. El Grupo de Oviedo, "Historia y Política", no 8, Madrid, noviembre de 2002.

31 Fragmentos de mis Memorias, op. cit. pág. 182.

32 Entre las muchas traducciones que Posada llevó a cabo, aunque no ciertamente la más lograda, se encuentra la que hizo en 1902 de la obra de W. BAGEHOT The English Constitution, 
sada, además, participó en las actividades del Instituto Internacional de Sociología de París y del Círculo de Estudios Sociales de Génova, realizó algunos viajes académicos a Italia, Francia, Alemania, Inglaterra — la Universidad de Oxford le dejó una huella indeleble- Holanda, Bélgica y Suiza; ejerció como Bibliotecario de la Facultad de Derecho, aumentando de forma muy considerable sus fondos; participó en París, en 1894, junto a Alvarez-Buylla y a Sela, en la creación del moderno movimiento olímpico internacional; y asistió a diversos Congresos nacionales e internacionales, como el Congreso Pedagógico de 1898 o el Congreso Hispano-americano de 1900, que supuso una importancia afirmación de un nuevo y fecundo americanismo, superador de los viejos esquemas paternalistas y neocoloniales. La política americanista de colaboración académica e intercambio docente con centros universitarios de Hispano-América (en aquel entonces a ningún español, por afrancesado que fuese, se le ocurría hablar de "América Latina") culminaría en 1909 con el viaje a América de Rafael Altamira en 1909, que allanaría el camino a otros viajes de Posada, a los que luego me referiré33.

Otras de las preocupaciones fundamentales de Posada durante su permanencia en la Universidad asturiana - en realidad, durante toda su vidafue la "cuestión social". Preocupación común a los krausistas y, en particular, al grupo de Oviedo. Posada confiesa en sus Memorias que antes de que el siglo XIX terminase creía

"urgente una transformación del viejo liberalismo individualista, abstracto, de mero laissez-faire, tan necesitado del influjo de lo que yo había de llamar "fluido ético", idea que, andando el tiempo, constituiría el eje central de mi teoría - y práctica- del Derecho y del Estado „34.

En 1902, José Canalejas, Ministro del Gabinete Sagasta, hombre muy próximo al krausismo y máximo exponente del nuevo liberalismo social o de izquierda (una expresión que en modo alguno es un oxímoron, como hoy se cree en esta España desmemoriada), se dispuso a crear un Instituto de Trabajo $^{35}$. Para tal propósito requirió la asesoría de Buylla y Posada, quien habla

que acaba de reeditar el CEPC, con un extenso Estudio preliminar a mi cargo, en cuyo último apartado examino la huella de la obra del ensayista inglés en España desde la revolución de 1868 hasta la II República, también, por supuesto, en el propio Posada.

33 Sobre la política americanista de la Universidad de Oviedo, vid. dos trabajos de S. MELÓN FERNÁNDEZ, El viaje a América del profesor Altamira y Las grandes etapas del hispano-americanismo, ambos en Estudios sobre la Universidad de Oviedo, op. cit. págs. 115-173 y 207-227, respectivamente.

34 Fragmentos de mis Memorias, op. cit. pág. 281. “Era urgentísimo — escribe más adelanteromper con la tradición o manía abstencionista del partido liberal español, que se caía de viejo, y lanzarse resueltamente al intervencionismo del Estado, dándole al liberalismo la sustancia social de que carecía...”, ibidem, pág. 293.

35 Sobre el Instituto de Trabajo, vid. A. BUYLLA, A. POSADA y L. MOROTE, El Instituto del Trabajo. Datos para la historia de la reforma social en España, con un Discurso Preliminar de J. CANALEJAS y MÉNDEZ y una Memoria acerca de los Institutos de Trabajo en el extranjero por J. UÑA 
con mucha admiración en sus Memorias del político gallego ${ }^{36}$. Este proyecto fracasó, pero merced a él el Gabinete presidido por Francisco Silvela aprobó al año siguiente un Real Decreto que ponía en pie el Instituto de Reformas Sociales, dirigido por Gumersindo de Azcarate. Precisamente, Posada se trasladó a Madrid en 1904 para incorporarse a este Instituto, en donde trabajó hasta su desaparición en 1924. Se cerraba, así, su ciclo de catedrático en Oviedo.

\section{EN EL INSTITUTO DE REFORMAS SOCIALES Y EN LA UNIVERSIDAD MADRILEÑA}

Durante los veinte años que permaneció en el Instituto —al que algunos liberales a la vieja usanza llamaban "Instituto de vacunación socialista" ${ }^{37}$ - Posada se ocupó de la sección de Bibliografía y Legislación, cargo que llevaba anexo el de redactor-jefe de un Boletín y el cometido de estudiar y dictaminar las disposiciones normativas de contenido social, con el objeto de proponer al Gobierno su reforma o su sustitución por nuevos proyectos de Ley. De manera que puede decirse que el origen del moderno derecho laboral está indisociablemente asociado al nombre de Adolfo Posada ${ }^{38}$.

Durante estos años se produjo en nuestro país un notable desarrollo económico, auspiciado por la repatriación de capitales de las últimas colonias y por la neutralidad de España durante la I Guerra Mundial, que vino acompañado de una gran agitación social, en parte por la carestía y la escasez de bienes de primera necesidad. A este respecto, conviene recordar que Posada, como los demás krausistas, enfocaba la cuestión social desde una perspectiva reformista y "armónica", tan alejada del miope egoísmo de la derecha española como de los sueños revolucionarios de la izquierda socialista o anarquista, convertidos en pesadilla después de la revolución soviética de 1917.

En el orden político, las dos primeras décadas del siglo se caracterizaron por la crisis de la Restauración, acelerada por la descomposición de los partidos turnantes, sobre todo después del fracaso de Maura y del asesinato de

y SARTHOU, Madrid, 1902, edicición facsímil de 1986 a cargo del Ministerio de Trabajo y Seguridad Social, con un Prólogo de S. CASTILLO.

36 CANALEJAS, escribe Posada, llegó a ser "uno de mis más cordiales e íntimos amigos", Fragmentos de mis Memorias, op. cit. págs. 119. "Fue Canalejas —añade- el político español con quien tuve mayor intimidad y de quien he recibido mayores y más patentes pruebas de estimación, afecto y confianza... Cfr. Ibidem, pág. 291. Una reciente e interesante semblanza biográficopolítica de CANALEJAS puede verse en J. MORENO LUZÓN, José Canalejas. La democracia, el Estado y la nación, incluido en el libro, coordinador por este autor, Progresistas, Taurus, Madrid, 2006, págs. 161-193.

37 Cfr. Fragmentos de mis Memorias, op. cit., pág. 298.

38 Sobre la labor del Instituto de Reformas Sociales vid. A. MARTÍN VALVERDE, La Formación del Derecho del Trabajo en España, Estudio Preliminar a La Legislación Social en la Historia de España. De La Revolución Liberal a 1936, Publicaciones del Congreso de los Diputados, Madrid, 1987, págs. XLVIII-LXXVII. 
Canalejas, en 1912, tan sentido por Posada, en medio de una desastrosa guerra colonial en Marruecos, a resultas de la cual arreciaron las críticas de buena parte de la sociedad contra el Ejército y contra el propio Rey, Alfonso XIII. En este contexto, tuvo lugar un importante auge del Partido Socialista, en cuya prensa colaboró Posada con asiduidad ${ }^{39}$, así como de los nacionalismos periféricos y del republicanismo. Mención especial merece la creación del Partido Reformista por Gumersindo de Azcárate y por el gijonés Melquíades Álvarez, uno de los discípulos más destacados de Posada, al que sólo llevaba cuatro años. En el Partido Reformista, junto a su primo José Manuel Pedregal, militó Posada desde su fundación, en 1912, hasta los primeros años de la II República, siendo elegido Senador por Asturias entre 1920 y 1923.

Aunque durante los primeros seis años Posada se volcó en las actividades del Instituto de Reformas Sociales, a partir de 1910 el profesor asturiano reanudaría el estudio del Derecho Político, de la Sociología y de la Administración Local. A esta última dedicó buena parte de su atención desde su acceso, en 1910, a la flamante cátedra de Derecho Municipal Comparado en la Universidad Central de Madrid, creada en el marco de los cursos de doctorado impartidos por esta Universidad y entre cuyos alumnos Posada recuerda en sus Memorias a José Antonio Primo de Rivera, a José Calvo Sotelo, a José María Gil Robles y a Lepoldo Alas y García Argüelles, hijo de su querido amigo "Clarín" y fusilado más tarde por los franquistas cuando era Rector de la Universidad de Oviedo. Durante esta época Posada continuó enseñando también en la Institución Libre de Enseñanza, de la que llegó a ser Vicerector de Estudios, y en 1907 aceptó formar parte de la Junta para el Fomento de la Educación Nacional. Un organismo que Canalejas presidió en 1910 y que llevó a cabo una encomiable política educativa, apoyada por Rafael Altamira desde la Dirección General de Enseñanza Primaria.

En 1910, pensionado por la Junta para la Ampliación de Estudios —otra gran creación del krausismo, junto a la Residencia de Estudiantes- Posada, en sustitución de Santiago Ramón y Cajal, que se encontraba enfermo, emprendió un viaje por Argentina, Chile, Uruguay y Paraguay, acompañado de su hijo Carlos. Este viaje contribuyó a reforzar los lazos académicos e intelectuales entre estos países y España y, desde luego, a difundir la obra del profesor asturiano, sobre todo en Argentina, a donde volvería en 1922. Su primer contacto con la América hispana le impactó sobremanera, como no podía dejar de ser en un gran patriota como él:

«alcancé, o logré, entonces — recuerda en sus Memorias — la más justa visión y comprensión de la grandeza de España. América, la América hispana, escuela de patriotismo, no hay duda. Porque, a mi ver, el valor de España sube, se eleva a lo más alto, en o desde nuestra América, obra de los españoles de España ${ }^{40}$.

39 Cfr. LAPORTA, op. cit. págs. 72-73.

40 Fragmentos de mis Memorias, op. cit., pág. 344. 
Europeísmo e hispanoamericanismo se funden, así, en Posada, como en la mejor tradición liberal española.

Entre el primer y el segundo viaje a la América de lengua española, Posada asistió en Washington, en representación de España, a la Conferencia Internacional del Trabajo, celebrada en 1913.

En 1920 — sin dejar su Cátedra de doctorado en Derecho Municipal Comparado- accedió a la Cátedra de Derecho Político de la Universidad Central, que había dejado vacante Santamaría de Paredes. Con ello confiesa Posada que se había realizado su sueño. "Desempeñar esa cátedra de la Universidad Central fue una ambición —un anhelo- que hasta entonces no había logrado satisfacer ${ }^{41}$.

A resultas del golpe militar de Primo de Rivera, en septiembre de 1923, Posada dimitió de los cargos que entonces ocupaba en el Instituto Nacional de Previsión y en el Consejo de Instrucción Pública, concentrándose en su Cátedra universitaria. En 1929 no dudará en elevar una protesta individual al Gobierno de la Dictadura por su política universitaria represiva, entre cuyas víctimas se encontraban Miguel de Unamuno, castigado con el destierro, así como José Ortega y Gasset, Luis Jiménez de Asúa y Fernando de los Ríos, que se vieron obligados a renunciar a sus cátedras ${ }^{42}$. En 1930 publica El Régimen Constitucional. Esencia y formas. Principios y técnica y al año siguiente Hacia un nuevo Derecho Político y La Reforma Constitucional, este último sobre un asunto de candente actualidad entonces.

\section{LA JUBILACIÓN, EL EXILIO, LA MUERTE}

A los pocos días de proclamarse la II República, Posada se jubiló como catedrático -él confesará en sus Memorias que lo jubilaron de forma "precipitada "43 - pero el claustro de la Facultad de Derecho de la Universidad Central acordó por unanimidad designarle Decano, así como crear en su honor el "Instituto González Posada de Derecho Público".

En realidad, Posada se vio desbordado por el nuevo ambiente político, como le ocurrió a Melquíades Álvarez y a otros antiguos militantes del Partido Reformista, que se disolvió poco después de asentarse el régimen republicano.

Aunque Posada aceptó el encargo de formar parte de una Comisión Jurídica Asesora encargada de elaborar un anteproyecto de Constitución - muchas de cuyas propuestas no prosperaron, como en lo que atañe a la estructura de las Cortes, a la elección del Presidente de la República, a las relaciones entre la Iglesia y el Estado y al estatus de la propiedad privada- el veterano catedrático volvió a centrar casi todas sus energías, que seguían siendo mu-

41 Ibidem, pág. 345.

42 Cfr. LAPORTA, op. cit. págs. 79-80.

43 Fragmentos de mis Memorias, op. cit., pág. 177. 
chas, pese a su ya avanzada edad, en el Instituto de Derecho Público que llevaba su nombre, sin que ello le impidiese escribir varios libros más. Entre ellos La Nouvelle Constitution espagnole. Le régime constitutionnel en Espagne. Evolution, textes, comentaires ${ }^{44}$, escrito cuando ya había sobrepasado los setenta y un años de edad e inmediatamente después de que el nuevo texto constitucional español entrase en vigor.

Si bien el propósito primordial de este libro fue examinar la Constitución republicana, es preciso tener en cuenta que en él —como se indica en el propio título- se analiza también la evolución histórica del constitucionalismo español, a la que dedica poco menos de la mitad de sus páginas. En realidad, incluso cuando comenta la nueva Constitución, Posada hace continuas referencias a la historia constitucional española —que, por cierto, nunca había sido objeto preferente de su labor investigadora ${ }^{45}$ - pues, como señala en este libro, "ni el advenimiento" de la nueva Constitución republicana, "ni la significación del acto con el que se pretende darle forma jurídica pueden comprenderse y explicarse si se les considera al margen de sus lazos históricos ${ }^{46}$. Posada reconoce que el advenimiento pacífico de la República suponía:

«la aniquilación en el Estado oficial de los obstáculos tradicionales y la más decidida tentativa que se haya operado en España de instaurar un régimen constitucional sin la oposición de las inclinaciones dinásticas, del predominio del sentimiento y del interés confesionales de la Iglesia y de la tara del autoritarismo militar: todo esto tras más de un siglo de fracasos".

Sin embargo, no dejaba de advertir a continuación de los peligros que acechaban a la hora de elaborar una nueva Constitución, sobre todo por

«la amenaza siempre de un desbordamiento de democracia igualitaria, que puede llevar a lo que Giner (de los Ríos ) llamaba "el despotismo de la libertad", impío, sacrílego, que por desgracia no bajó a la tumba con Robespierre, ${ }^{47}$.

44 Sirey, Paris, 1932. El libro venía precedido de un prefacio a cargo de dos prestigiosos constitucionalistas franceses, J. BARTHÉLEMY y B. MIRKINE-GUETZÉVICHT, miembros correspondientes de la Academia española de Ciencias Morales y Políticas.

45 Lo que no fue óbice para que le dedicase algún trabajo, como la introducción a los, hasta entonces inéditos Principios de la Moral, la Política y la Legislación, que su paisano F. MARTÍNEZ MARINA había escrito durante la "década ominosa" y que vieron la luz por primera vez en 1933, editados por la Academia de Ciencias Morales y Políticas. Esta obra, con la introducción de Posada, se reeditaría en 1993 en el marco de la mencionada colección de "Clasicos Asturianos del Pensamiento Político", con un largo Estudio preliminar a mi cargo.

46 A. POSADA, La nueva Constitución española. El régimen constitucional en España. Evolución, textos, comentarios, INAP, Madrid, 2006, pág. 125. Las cursivas son de POSADA. Para esta edición bilingüe escribí un Estudio Preliminar, titulado "Adolfo Posada y la Constitución Española de 1931".

47 Ibidem, págs. 126-7. 
En una de las páginas más lúcidas de este libro — sin duda muy interesante para calibrar no sólo la actitud de Posada sobre la nueva Constitución, sino también para conocer algunos detalles de interés sobre la elaboración de este texto- el ya anciano catedrático asturiano pone de relieve que los Constituyentes de 1931 tuvieron que hacer frente a los graves problemas políticos y sociales que la monarquía constitucional no había sido capaz de resolver y que la Dictadura había agravado, como el problema de la propiedad de la tierra, la cuestión religiosa y la organización territorial del Estado. Y tuvieron que hacerlo, además, «bajo la influencia de las grandes transformaciones políticas y sociales de la post-guerra". El peligro se encontraba - como de hecho ha ocurrido- (añade Posada) en que para responder a estos problemas se incurriese en un "brutal" y "doloroso revanchismo", explicable, pero no justificado, por la secular injusticia social, que afectaba a la mayoría de la población, por "la desconsiderada forma" con que la Iglesia católica había "disfrutado de sus privilegios", y por el "espíritu mezquino de la centralización administrativa" iniciada en Cádiz ${ }^{48}$.

En cualquier caso, Posada reconoce que el proceso político abierto el 14 de abril del 31 "debía continuar la historia de España", pero no la de Cánovas, ni la de la Primera República. Desde un punto de vista estrictamente constitucional, ello significaba que la nueva Constitución no podía "enlazar" con la de 1876" ni tampoco "resucitar" la de $1869^{49}$. Más bien debía tener como punto de referencia los textos constitucionales extranjeros más recientes, nacidos durante o tras el fin de la Primera Guerra Mundial. Unos textos que el propio Posada se había encargado de dar a conocer, a veces con la ayuda de su joven discípulo Nicolás Pérez Serrano, con quien había editado en 1927 un libro titulado "Constituciones de Europa y América " ${ }^{50}$, en el que se recogían y comentaban, entre otras muchas, la mexicana de 1917, la alemana de 1919 — la llamada Constitución de Weimar-, la austriaca de 1920 y la checoslovaca de ese mismo año, que fueron las Constituciones que sirvieron de modelo a los constituyentes de 1931, sobre todo la alemana y la austríaca, en cuyo alumbramiento habían desempeñado un descollante papel Hugo Preuss y Hans Kelsen, respectivamente. Dos juristas bien conocidos - aunque este último no aceptado por entero, ni mucho menos- por sus colegas españoles, empapados de cultura germánica, como el propio Posada, maestro de buena parte de ellos.

El juicio de Posada sobre la nueva Constitución española era en general positivo, aunque no exento de muchos matices. Justo antes de concluir su libro, insiste, además, en que en aquel entonces la Constitución era sólo

"un signo de interrogación en la historia de un pueblo. El tiempo dirá... Como toda Constitución escrita sólo es un proyecto sobre el papel... el problema abierto, misterio del futuro, es el de saber si la nueva Constitución representa el esfuerzo o el impulso inicial apropiado para dar satisfacción al

48 Ibidem, pág. 63.

49 Ibidem, pág. 64.

50 Librería General de Victoriano Suárez, Madrid, 1927, 2 vol. 
deseo del pueblo español de establecer un régimen jurídico de libertades y vivirlo... Toda apreciación crítica del conjunto de la Constitución sería sin duda precipitada, en tanto no funcione total y normalmente su mecanismo desde el motor electoral, y sus recursos, frenos y contrafrenos...

!Ahi y el espíritu, en todo y sobre todo"

Después de escribir su libro sobre la Constitución de 1931, Posada siguió dedicándose a sus actividades académicas en el mencionado Instituto de Derecho Público que llevaba su nombre. De su refugio académico intentó sacarle Niceto Alcalá Zamora el 7 de octubre de 1933 - año en que publica un nuevo libro: El Derecho Político como espectáculo, Cincuenta años de Cáte$d r a^{51}$ — cuando le ofreció presidir el Consejo de Ministros, tras la dimisión de Alejandro Lerroux. Pero Posada declinó la oferta del Presidente de la República — como antes habían hecho Sánchez Román, Manuel Pedregal y Gregorio Marañón- que finalmente aceptó Diego Martínez Barrio, que es quien lo cuenta en sus Memorias ${ }^{52}$.

En 1934 publica Posada un nuevo libro, La Crisis del Estado y el Derecho Político, mientras que al año siguiente aparece la quinta edición, la última en vida de su autor, del Tratado de Derecho Político, en la que dedica tan sólo veinte páginas a la Constitución de $1931^{53}$.

Ese mismo año de 1935 aceptó presidir el Instituto Nacional de Previsión, cargo del que le destituyó al año siguiente el Gobierno del Frente Popular, al igual que del Decanato de la Facultad de Derecho de la Universidad de Madrid. "Causa académica de mi destitución-escribe Posada, con irónica cursiva en sus Memorias-: que yo no pertenecía al Frente Popular, ${ }^{54}$.

En esta misma obra, Posada recuerda que "en el otoño trágico de 1936" su "hogar de Madrid fue arrasado", muchos de sus libros "convertidos en ladrillos de trincheras", y "destrozados, quemados o embarrizados" los papeles que había ido almacenando para escribir sus memorias ${ }^{55}$. No sorprende, pues, que con estos hechos - junto a otros más trágicos, como el asesinato en agosto de ese año de Melquíades Álvarez, encarcelado en la madrileña cárcel ModeloPosada decidiese exiliarse en San Juan de Luz, cuando era un anciano de 76 años. Allí permaneció hasta 1939. Ese año decidió regresar a Madrid, rehusando los ofrecimientos que le hicieron para asentarse en la Argentina. En la capital de España murió el 8 de julio de 1944.

51 Tipografía de Archivos, Madrid, 1933.

52 Planeta, Barcelona, 1982, pág. 200.

53 Cfr. Tratado de Derecho Político, $5^{a}$ edición revisada, Librería General de Victoriano Suárez, Madrid, 1935, tomo segundo, págs. 308-328. Es muy probable que a POSADA no le gustase mucho la forma en que los políticos republicanos aplicación la Constitución de 1931, pero en cualquier caso la escasa atención que le prestó se explica tanto por su ya comentada concepción del Derecho Político, como por su hincapié en el estudio de las doctrinas, de las Constituciones y de las instituciones extranjeras en vez de en las españolas.

54 Fragmentos de mis Memorias, op. cit., pág. 178.

55 Ibidem, pág. 320. 
TrtLE: Adolfo Posada's individual and political career.

ABstRact: Adolfo González Posada (Oviedo, 1860 - Madrid, 1944) was the most influential Theory of the State, Sociology and Political Science's Spanish researcher all along the two last decades of the XIXth century and the three first decades of the XXth century. In this biography I firstly examine his intellectual training under the krausism's influence and particularly that of Francisco Giner de los Ríos and Gumersindo de Azcárate. Next, I analize his fruitful activity between 1893 and 1904 as a Professor at the University of Oviedo, where he not only wrote many important books, such as the "Tratado de Derecho Politico", his more outstanding work, but also carryied out a relevant activity of cultural divulgation. The following pages deal with his activity in the "Instituto de Reformas Sociales", from 1904 until 1924, and in the University of Madrid, as well as his collaboration with the "Partido Reformista". I finish this study including a few words about his life and work from the proclamation of the Second Republic until his dead, after a painful exile as a result of the Spanish Civil War.

Resumen: Adolfo González Posada (Oviedo, 1860- Madrid, 1944) fue el más influyente cultivador español de la Teoria del Estado, la Sociología y la Ciencia Política durante las dos últimas décadas del siglo XIX y las tres primeras del XX. En esta semblanza examino, en primer lugar, sus años de formación bajo el decisivo ascendente del krausismo y en particular de Francisco Giner de los Ríos y de Gumersindo de Azcárate. Analizo a continuación su fecunda labor, entre 1893 y 1904, como Catedrático en la Universidad de Oviedo, en la que además de escribir numerosos trabajos, entre ellos el "Tratado de Derecho Político", su obra cumbre, llevó a cabo una fructífera labor de divulgación cultural. Las páginas siguientes se ocupan de su actividad en el Instituto de Reformas Sociales, desde 1904 a 1924, en el Partido Reformista y en la Universidad madrileña. Concluyo esta semblanza con una exposición de su vida y obra desde la proclamación de la II República hasta su muerte, tras un penoso exilio a resultas de la Guerra Civil.

Key words: Adolfo Posada. Theory of the State. Sociology. Political Science.Iintelectual and political history of contemporary Spain.

Palabras clave: Adolfo Posada. Teoría del Estado. Sociología. Ciencia Política. Historia intelectual y política de la España contemporánea. 